\title{
Metal-free Electrocatalyst for Hydrogen Production from Water
}

\author{
A.V. Dolganov ${ }^{1, *}$, B.S. Tanaseichuk ${ }^{1}$, P.M. Ivantsova ${ }^{2}$ Y.V. Tsebulaeva ${ }^{l}$, S.G. Kostrukov ${ }^{1}$, \\ D.N. Moiseeval, N.M. Shmelkova ${ }^{1}$, V.Y. Yurova ${ }^{l}$, O.I. Balakireval, N. N. Trushkoval, I.G. Nagaeval. \\ ${ }^{1}$ Department of Chemistry, Mordovian Ogarev State University, Saransk 430005, \\ Russia \\ ${ }^{2}$ Department of Chemistry, M.V. Lomonosov Moscow State University, Leninskie Gory 1/3, Moscow, \\ Russian Federation \\ *E-mail: dolganov_sasha@mail.ru
}

doi: $10.20964 / 2016.11 .24$

Received: 8 August 2016 / Accepted: 31 August 2016 / Published: 10 October 2016

Here we report organic metal-free catalyst - 9-phenyl-10-methylacridinium iodide (PhAcrI) for hydrogen evolution reaction (HER) from water at $\mathrm{pH}$ from 1 to 4 . With increasing $\mathrm{pH}$ to 7 HER, according to the GA analysis of the HER is not observed. The catalytic nature of the reduction wave $\mathrm{PhAcr}^{+} / \mathrm{PhAcr}{ }^{*}$ was confirmed by controlled potential electrolysis experiments with a simultaneous quantitative detection of hydrogen evolved. PhAcrI at low $\mathrm{pH}$ reacts via protonation of an $\mathrm{PhAcr}$ intermediate that subsequently forms $\mathrm{H}_{2}$ via a homolytic mechanism.

Keywords: HER, Metal-free electrocatalyst, aqueous solution, 9-phenyl-10-methylacridinium iodide

\section{$\underline{\text { FULL TEXT }}$}

(C) 2016 The Authors. Published by ESG (www.electrochemsci.org). This article is an open access article distributed under the terms and conditions of the Creative Commons Attribution license (http://creativecommons.org/licenses/by/4.0/). 